blinded, prospective, randomized study of 210 patients. Ann Thorac Surg 1996;61:1131-5.

2. Karski JM, Teasdale SJ, Norman P, et al. Prevention of bleeding after cardiopulmonary bypass with high-dose tranexamic acid: double-blind, randomized clinical trial. J Thorac Cardiovasc Surg 1995;110:835-42.
3. Karski JM, Teasdale SJ, Norman PH, Carroll JA, Weisel RD, Glynn MFX. Prevention of postbypass bleeding with tranexamic acid and z-aminocaproic acid. J Cardiothorac Vasc Anesth 1993;7:431-5.

4. Soslou G, Horrow J, Brodsky I. Effect of tranexamic acid on platelet ADP during extracorporeal circulation. Am J Hematol 1991;38:113-9.

\title{
POSTOPERATIVE RIGHT VENTRICULAR DYSFUNCTION RELATED TO AN UNEXPECTED LATE FATAL COMPLICATION
}

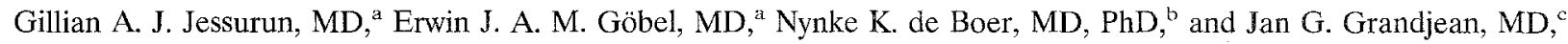
Groningen, The Netherlands

At present, aspirin is the first-line antithrombotic therapy for patients after coronary artery bypass grafting. The evaluation of postoperative coronary graft patency data suggests that dipyridamole in addition to low-dose aspirin does not improve aorta-coronary artery vein graft occlusion rate. Moreover, compared with aspirin, oral anticoagulants provided no benefit. ${ }^{1}$ In most clinics for heart surgery the antithrombotic postoperative regimen constitutes low-dose aspirin at discharge. Coumarins are reserved for those patients with artificial valves and moderate to severe areas of dyskinesia or akinesia after left ventricular infarctions or cardiomyopathy. However, we present a pertinent clinical observation that should alert clinicians to the necessity of optimal oral anticoagulation in patients with postoperative transient right ventricular dysfunction or the presence of right-sided cardiomyopathy.

A 41-year-old man had an anterior myocardial infarction 6 years before admission, for which he received thrombolysis. This was followed by a rescue percutaneous transluminal coronary angioplasty of the significant residual stenosis in the left anterior descending coronary artery. One year thereafter he underwent an angioplasty of the right coronary artery, with a second angioplasty for a restenosis of the right coronary artery. In June 1996 he was admitted with unstable angina pectoris. His chest symptoms remained refractory to treatment with intravenous heparin, high-dose nitroglycerin, aspirin, and a $\beta$-adrenergic blocker. Subsequently, coronary angiography re-

From University Hospital Groningen, Departments of Cardiolo$\mathrm{gy}^{\mathrm{a}}{ }^{\mathrm{C}}$ Pathology, ${ }^{\mathrm{b}}$ and Thoracic Surgery, ${ }^{\mathrm{c}}$ Groningen, The Netherlands.

Received for publication Sept. 20, 1996; accepted for publication Oct. 24, 1996.

Address for reprints: Gillian A. J. Jessurun, MD, Department of Cardiology, University Hospital Groningen, Hanzeplein 1, Groningen $9700 \mathrm{RB}$, The Netherlands.

J Thorac Cardiovasc Surg 1997;113:804-5

Copyright (C) 1997 by Mosby-Year Book, Inc.

$0022-5223 / 97 \$ 5.00+0 \quad \mathbf{1 2 / 5 4 / 7 8 9 2 8}$ vealed slightly impaired left ventricular function with hypokinesis of the anterior wall, a subtotal right coronary artery occlusion, significant left main stenosis, an $80 \%$ lesion of the circumflex coronary artery, and a $70 \%$ stenosis of the midportion of the left anterior descending coronary artery. Coronary artery bypass grafting was performed under clinically stable conditions. The left thoracic artery was anastomosed to the left anterior descending coronary artery. The right thoracic artery was routed through the transverse sinus and anastomosed to the marginal branch of the circumflex artery. The gastroepiploic artery was anastomosed to the right posterior descending coronary artery. In addition, an endarterectomy of the right coronary artery was performed because of severe right ventricular dysfunction during an attempt to wean the patient from extracorporeal circulation. However, after the operation the patient had a right ventricular infarction. Volume loading and inotropic support were necessary to wean the patient from the ventilator. Echocardiography revealed a dilated right ventricle with severely depressed systolic function. No pericardial effusion and no signs of intracavitary thrombus were present. He had a protracted clinical recovery. One month after admission he was discharged in stable condition. His medication consisted of bumetanide, digoxin, and aspirin $100 \mathrm{mg} /$ day.

Four weeks after discharge he was readmitted with severe exertional dyspnea (New York Heart Association class IV), tachypnea, and bilateral external jugular venous distention but no pulmonary or peripheral edema. The second heart sound was loud and variably split. The electrocardiogram demonstrated sinus tachycardia, left posterior hemiblock, and an incomplete right bundle branch block. Findings on the chest $x$-ray film were within normal limits. Repeated echocardiography revealed a persistently dilated right ventricle with improved systolic function and no signs of a thrombotic mass. A ventilation/ perfusion scan revealed extensive mismatch in both lungs compatible with a high probability for pulmonary embolism. Streptokinase was administered intravenously because of subsequent hemodynamic deterioration as a 


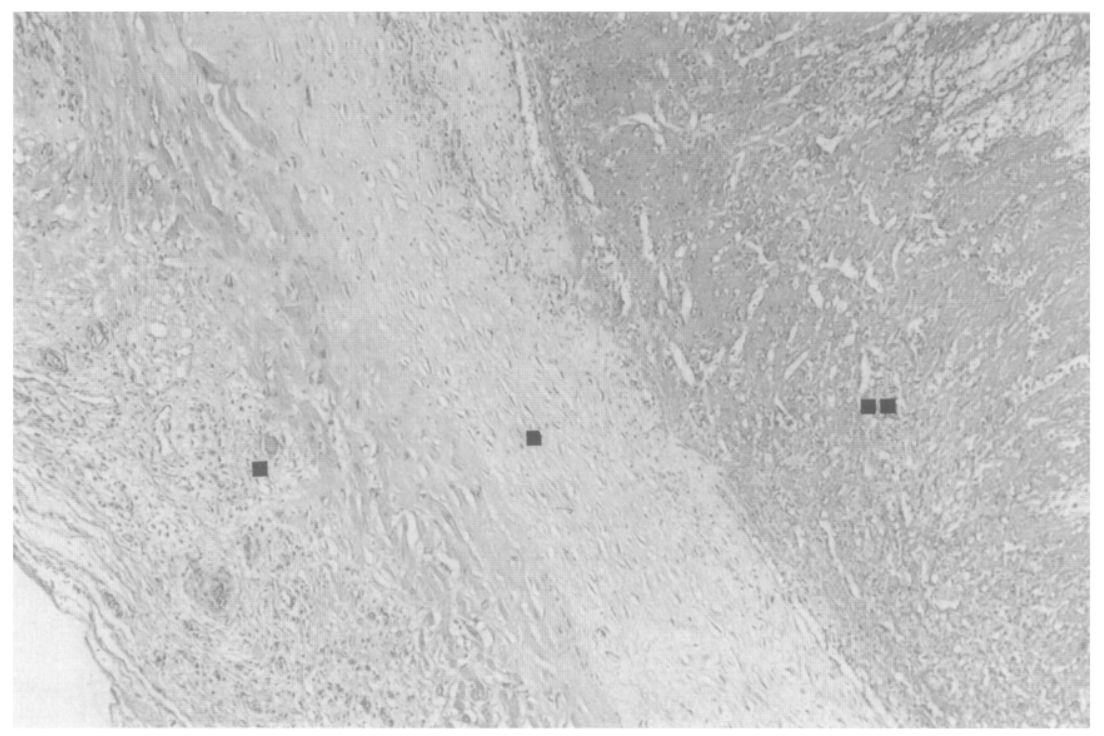

Fig. 1. A section through the posterior wall of the right ventricle shows an old transmural myocardial infarction with replacement of necrotic fibers by a fibrous scar (one black square). Attached to the thickened endocardium is a mural thrombus with organization (two black squares). (Original magnification $\times 16$.)

bolus of $2000 \mathrm{U} / \mathrm{kg}$, followed by $2000 \mathrm{U} / \mathrm{kg}$ per hour. Despite subsequent resuscitative efforts the patient died of an electromechanical dissociation. Postmortem examination revealed an enlarged heart with scar tissue in the posteroseptal area. The dilated right ventricle demonstrated several mural thrombotic masses adherent to scarred endocardium between the trabeculae at the posterior region of the right ventricular wall (Fig. 1). The size of the thrombotic material ranged from 1.2 to $3.5 \mathrm{~cm}$. The coronary arteries were severely narrowed proximally to the bypass grafts. All the grafts and anastomoses were patent. There were multiple thromboemboli in both lungs.

Few cases of lethal pulmonary emboli originating from mural thrombi in the right ventricle have been described. $^{2,3}$ Many physicians neglect the true risk for right ventricular thrombus formation in patients with right ventricular dilatation related to infarction and right-sided cardiomyopathy. ${ }^{4}$ The predisposing thrombogenic risk factors are (1) dilatation and stunning after transmural injury of the relatively thin-walled right ventricle, (2) an increased resistance to diastolic filling, (3) decreased pulmonary perfusion caused by a depressed right ventricular systolic function in the absence of a left ventricular septal contraction (in our patient the loss of this compensatory mechanism was caused by a concomitant or old septal myocardial infarction), and (4) superficial or ulcerative endocardial injury, blood stasis, and longstanding reduction of right ventricular systolic pressure contributing to thrombosis. ${ }^{5}$ Owing to the rarity of the right ventricle as the source of pulmonary embolism, mural thrombi are often overlooked or not pursued diagnostically. Echocardiography may be unsuitable to detect mural thrombi because muscular trabeculae and chordae may mask the presence of possible thrombotic masses.

We suggest that patients with postoperative right ventricular dysfunction, even transiently, should be considered to be at risk for thromboembolic complications. Careful echocardiographic evaluation for right-sided mural thrombi must be followed by adequate prophylactic anticoagulant therapy.

\section{REFERENCES}

1. van der Meer J, Hillege HL, Kootstra GJ, et al. Prevention of one-year vein-graft occlusion after aortocoronary-bypass surgery: a comparison of low dose aspirin, low-dose aspirin plus dipyridamole, and oral anticoagulants. Lancet 1993;342:25764.

2. Ahdout DJ, Damani PM, Ultan LB. Recurrent acute pulmonary emboli in association with acute myocardial infarction. Chest 1989;96:862-84.

3. Harris KM, Haney MF, Gerling B. Plehn JF. Systemic embolization complicating right ventricular myocardial infarction. Arch Intern Med 1995;155:111-3.

4. Corrado D, Thiene G, Nava A, Rossi L, Pennelli N. Sudden death in young competitive athletes: clinicopathologic correlations in 22 cases. Am J Med 1990;89:588-96.

5. Kinch JW, Ryan TJ. Right ventricular infarction. N Engl J Med 1994;330:1211-7. 